\title{
Waiting by the Water's Edge-Seated Qigong with Seniors in Long-Term Care ${ }_{1}$
}

\author{
Bernie Warren*, Joanna Coughlin BA, Meagan Littlejohn BHK, Adrienne Campbell BA and Alora Warren B Kin \\ University of Windsor, Canada \\ Submission: February 12, 2018; Published: March 09, 2018 \\ *Corresponding author: Bernie Warren*Ph.D, Professor Emeritus, Drama in Education and Community, SODA, University of Windsor/Owner, \\ Bear Moves Mountains c/o 22 Mill St W. Leamington N8H 1S8, Canada, Email: merv123@uwindsor.ca
}

\begin{abstract}
In the summer of 2012 I began to offer Seated Qigong programs at a newly opened "long-term care and retirement village" in South Western Ontario. This program continued through to my own retirement in 2016. In the first year of the program we conducted two different pieces of research, one for the pilot project and one during the start up phase of the program. During both phases we collected qualitative observational data and quantitative data concerning pre- and post- blood pressures \& heart rates. Waiting at the Water's Edge is a personal reflection that focuses primarily on the initial phase of the first year of the Seated Qigong program. It looks at the data we collected and the problems and successes of implementing the program and the health benefits to the many residents and staff who participated.
\end{abstract}

Keywords: Seated qigong; Health promotion; Seniors; Long-Term care; Dementia; Multiple health problems

\section{Tensions Between Water and Wood}

"No man ever steps in the same river twice,

For it's not the same river and he's not the same man ${ }^{3 \prime}$.

The image of water is always present in Qigong and Chinese Martial Arts'. This is an extension of Taoist philosophy, which talks of Tao as being a stream or a river. Taoist sages believe our lives are spent in this moving river of life where we must surf its wave(s) -not only those of our own making but also of the universe we inhabit. This is not always easy. We can surf in the same direction as the wave or we can ride along it but we cannot surf against its direction or else we are likely to 'fall off' our board. When this happens most of us simply pick ourselves up and get back on our surfboard, point it in the same direction as the wave and continue our journey. From a Taoist perspective we are always immersed in $\mathrm{TAO}^{5}$, but I believe that many people in longterm care in large part are no longer surfing the stream of their life. For in some ways many individuals in long-term care simply hand their surfboard to their well-meaning care givers, forcing them to sit passively by the water's edge and watch life go by. Here they reflect on their past and wait for the river to 'burst its banks' - for death to creep up to carry them away to oblivion ${ }^{6}$. By being 'forced' to step out of the stream of life, individuals in longterm care facilities start to ossify, to become less resilient and more like wood. Seated Qigong with emphasis on cultivating Chi, bio-electrical energy, through simple movements and breathing patterns helps reconnect people to TAO. Immersing in Qigong's simple breathing and movement patterns enriches participants and fills them with energy. For those in long-term care it can help transform their state of mind from simply passively waiting for things to happen to them, to being by the water's edge-providing the opportunity to actively engage in life's stream.

\section{Sitting by the Water's Edge -Quiet Beginnings}

In 2011, I met with Mike Sharrat at a Sheridan College Conference on Aging. Mike and I discussed conducting research on the Seated Qigong program I had previously developed at various senior's facilities and residences in Ontario. As a result of these conversations, in the summer of 2012 I began to offer Seated Qigong programs at a newly opened "long-term care and retirement village" in South Western Ontario. This long-term care facility had just hired, as their recreation co-ordinator, a long-time colleague and supporter of my Seated Qigong work with healthy seniors, and so it was an opportune moment to start this program. In the first year of the program we conducted two different pieces of research - one for the pilot project and one during the start up phase of the seated Qigong program. During both phases we collected qualitative observational data and quantitative data concerning pre- and post- blood pressures and heart rates $^{7}$. In time the program became more established. The work, which began slowly with a 12 -week pilot project continued 
through to my retirement from the University of Windsor in 2016. During this time Seated Qigong was delivered on three different neighbour hoods and in the library. The program was very successful and led to the delivery of similar programs at other long-term Care Facilities, several of which were led by Joanna Coughlin who was instrumental in the development of the initial pilot program. Waiting at the Water's Edge, the current paper, will focus primarily on the initial phase of the Seated Qigong program.

\section{Sitting-Breathing-Laughing Quietly, by the Water's Edge}

The Seated Qigong program I taught at the long-term care facility was developed over more than 20 years of teaching Qigong to people with life threatening and life changing conditions ${ }^{9}$. The exercises are simple, transportable, require no special equipment and can be done by participants on their own at home. Each class in the Seated Qigong program lasted 25-35 minutes in total. It included versions of: The Three Cleansing Breaths Qigong; Balancing the Heart Qigong; Triple Warmer Qigong; The Bad Duan Jin - all adapted to be performed seated and with little stress. It also included several classical Qigong cool down exercises ${ }^{10}$. All the classes were performed seated accompanied by soft relaxing music ${ }^{11}$. I intentionally used jokes and humour at points within the class to motivate residents to participate. While the program remained fairly constant I always adapted the activities, especially in terms of speed and number of repetitions, to meet the needs of the individuals present on any given day within each group. The Seated Qigong pilot program at the long-term care facility began in June 2012 and ran for 12 weeks. During this time we delivered a total of 22 classes. We worked with 2 groups - one that was at the "well senior" end of the spectrum, (although many used wheelchairs, all with different issues, disorders or illnesses e.g. cancer, high blood pressure, diabetes, heart attack); and one at the other end of the spectrum (individuals exhibited a mix of behavioural concerns and were living with Dementia, Parkinson's, strokes and many other conditions - often multiple ailments at one time). Participant numbers for each class fluctuated, ranging from 5-17.

\section{Reflections on Sitting by the Water -Everyone has his/ her Own Measuring Stick of Progress}

"I had no concept of what would be deemed improvements, so I decided to follow Bernie, participating in the movements and to keep a constant watch on the participants ${ }^{12}$.

Throughout the program several university students were hired as research assistants to help run the classes. In addition, they aided residents where needed; took blood pressures/heart rates and collected qualitative data by observing participants and through conversations with staff at the facility. Throughout the first year we recorded several significant responses from participants within the program. There were a few cases where progress was incredible. One resident stands out. She had severely restricted movement with very little control of her body or outer extremities. From the very first class, she spent the entire time sleeping. We noticed a few weeks later that she was staying awake longer and longer, eventually leading to full sessions without any sleep. We were intrigued to see her start to observe everybody, maintaining concentration and interest. In the last two weeks, there were points in the sessions she would gently rub her hands together to simulate what the rest of us were doing. When we would move our bodies in a circular motion she rotated her head along with us ${ }^{13}$. Sometimes a marker of progress was far less significant or obvious. Some days we had 20 people awake and fully participating in the session. On other days only 2-3 people turned up. Even when we had 20+ people in the room it was not unusual to have over $50 \%$ be or fall, asleep for at least part of the session. So a marker of success was as simple as observing that a resident, who was usually asleep or unresponsive:

... was engaged and awake for entire class; and followed along well with most movements ${ }^{14}$

Another small success was: ... (a resident) who does not normally stay for group exercises, stayed for the entire class and participated well ${ }^{15}$

Several people had conditions that made breathing during the day and especially at night very difficult. Often the condition was slightly exacerbated as these individuals tried very hard to "get it right".

(She) worked too hard for her current ability level. She became quite out of breath and continued the exercises even as her oxygen tank was taken to be refilled. She was red and sweaty by the end of the session ${ }^{16}$.

This "no pain, no gain" approach (i.e. the harder you work the more benefit from the exercise) is a Western approach to exercise which is in opposition to the practices of Qigong which emphasizes - "Less Effort, More Energy"; a slow relaxed approach where all movements are slow and synchronized with breathing. That said, there were also successes for several individuals. One resident let us know:

I was having a very difficult time breathing the night before but felt great after the class

Others mentioned they were able to use the exercises and approaches shown in our program to help with their breathing problems at other times during their day. One issue we dealt with, especially at the beginning, was with several residents who largely because of their medical conditions, exhibited disturbing and/or disruptive behaviours during class. For example a resident I will call $\mathrm{M}$, whom we were told was a very volatile and disruptive individual, attended Seated Qigong frequently.

M came to the class today and stayed for the entire class. It is interesting because he would not have been invited to the class due to his volatile nature, but it seemed to calm him 
M stayed calm throughout the class and did the majority of the exercises

As mentioned we took blood pressures and heart rate measurements throughout. In the pilot project the results were all over the map. Part of this was the "shock of the new" - people were unfamiliar with what was required and as a result some people did not follow the instructions for relaxed breathing with the movement. For others attendance was very inconsistent, also causing problems. All that being said there were some very interesting results. While there were some significant outliers, we did see overall reductions in one group, (the one with most consistent attendance!) in both diastolic and systolic $\mathrm{BP}^{17}$. Other very useful information came from unsolicited comments made by Personal Support Workers (PSW), other care staff and Nurses at the Long-term Care facility. Several of who stated that the residents seem much calmer after Qigong classes and this calmer state had a "half-life ${ }^{18 "}$ that often lasted long after the class was over. They also commented that since most of these residents are more active in the evening, they would benefit from evening classes. One PSW at the end of the class remarked that,

"It is so nice to see all of these residents so relaxed"

Another PSW who had joined in for some of the Qigong class commented:

"(Qigong) could be very beneficial for caregivers to decrease stress"

\section{Reflections in the Water - Final Observations}

I believe the evolutionary theory of natural selection can also be applied to programs delivered in healthcare settings. As best practice changes, as budgets shrink and as personnel changes so must programs change. Even well supported programs that do not evolve or who do not seem as "sexy" as the latest flavor of the month-are not as well supported by a facility, in terms of both finance and personnel, and so tend to fall by the wayside, wither ordie. The Seated Qigong program went through many phases and had many high points. During the lifetime of the program, like many similar programs, there were several factors that influenced the level of its success. One important factor was the decision, about 3 years into the program, by the recreation coordinator to leave to take a new job at a sister facility that had just opened. She was the initial catalyst for the program and in large part its unheralded cheerleader. Her departure affected attendance at the Qigong sessions, as this was always voluntary. Speaking of participant attendance, even when the program was at its height we experienced wildly different attendance figures. In part this was due to the day-to-day health of residents, many of whom were living with chronic and debilitating medical conditions. Other times, residents were 'depressed', usually over a family matter. Again one of the problems of long-term care facilities is that family members do not come to visit as often as residents would like. One of the more shocking points, especially for the younger program volunteers, is that when you are working with seniors with multiple health problems who are "waiting at the water's edge", inevitably some people just stop coming. This may be because they are no longer strong enough to get out of their beds or simply because they have passed on. In one case a man who loved our program did not appear for several sessions and eventually we discovered he had passed a week before. Some days it was difficult to tell if the residents could not participate in certain aspects of the class or if they merely would not. Above all else this program was voluntary and I surmise that participants came as much for my jokes and smiles as the Qigong. Overall, by any standard, measurable or intangible, the Seated Qigong program was a success. It brought smiles and short-term improved health to the many residents and staff who participated. The half-life of the program often lasted several days after the session. For many it was something they looked forward to every week and transformed their simply "waiting by the water's edge" to stepping into the river - if only for a brief period of time.

\footnotetext{
${ }^{1}$ This article builds on my previous article: Bernie W. Sit Smile Breathe - Seated Qigong for People with Life Changing Conditions: A Personal Reflection. J Complement Med Alt Healthcare. 2017; 1(3): 555562.

${ }^{2 *}$ Corresponding author: Professor Emeritus, Drama in Education and Community, University of Windsor/ Owner, Bear Moves Mountains 22 Mill St W. Leamington 0N Canada.Email; merv123@uwindsor.ca"merv123@uwindsor.ca

${ }^{3}$ Heraclitus, echoing Taoists sages who believed "you can not step into the same stream twice".

${ }^{4}$ Martial artists are always trying to find a balance in the "tension between rooting like a tree and flowing like water" - that sense of being both rooted and flowing. It is a delicate balance. From a Taoist perspective male martial artists have to work not to be too rooted. They are "wood" but they must strive not to become wooden. Whereas female martial artists are water and they must strive to seek roots.

${ }^{5}$ Within the context of traditional Chinese philosophy and religion, TAO is the intuitive knowing of "life" that cannot be grasped full-heartedly as just a concept but is known nonetheless through actual living experience of one's everyday being. For more start here: https://en.wikipedia.org/wiki/Tao ${ }^{6}$ This is not the case for everyone immediately they start living a long-term care home. Initially, some residents thrive in their new social environment of a care home making new friendships and social bonds that add significant happiness and enrichment to their lives. Unfortunately, as their physical health deteriorates even the most engaged person begins sitting and waiting.

${ }^{7}$ During the start up phase Cheri McGowan and I carried out, and later published significant research findings on the effects of the program on blood pressure and quality of life - Sit, breathe, smile: Effects of single and weekly seated Qigong on blood pressure and quality of life in long-term care Complementary Therapies in Clinical Practice 20 (2014) 48e53

${ }^{8}$ Like many long-term care facilities each floor was divided into neighbourhoods, each with a name familiar to residents e.g. Belle River. This helps develop a sense of community and enables residents and staff alike to know where 'home' is for each resident.

${ }^{9}$ E.g. Individuals: living with Parkinson's, Disease, Dementia, and Cancer; recovering from a heart attack and/or stroke; living with chronic debilitating conditions e.g. Lupus, Rheumatoid Arthritis, Diabetes, etc.

${ }^{10}$ For detailed descriptions see - Warren B, Coughlin J (2014) Stand Breathe Smile: Simple standing exercises and approaches to reduce stress and promote good health.
} 
${ }^{11}$ I often use selected tracks from - Deuter, "Wind And Mountain": https://deuter.bandcamp.com/album/wind-mountain

${ }^{12}$ Research Assistant Journals

${ }^{13}$ Research Assistant Journals

${ }^{14}$ Research Assistant Journals

${ }^{15}$ Research Assistant Journals

${ }^{16}$ Research Assistant Journals

${ }^{17}$ These initial results led to Cheri McGowan and I commencing our more detailed study.

${ }^{18} \mathrm{Half}$-Life is the time required for a quantity to reduce to half its initial value. It is most usually used to

This work is licensed under Creative

Commons Attribution 4.0 License

DOI: 10.19080/JCMAH.2018.05.555673 